\title{
Research on the Internal Mechanism of Economic Factor Coupling and High-quality Development: Empirical Evidence from the Greater Bay
}

\author{
Shizhong Xiong ${ }^{1, *}$ Xiaofang Xiong ${ }^{2}$ \\ ${ }^{1}$ Department of Accounting, Guangzhou Xinhua College, Guangzhou, Guangdong 510520, China \\ ${ }^{2}$ College of Innovation and Management, Suan Sunandha Rajabhat University, Bangkok 10300, Thailand \\ *Corresponding author. Email: xsz9293@126.com
}

\begin{abstract}
The economic transformation in the new era has broken the inherent order of factors such as economic mode, power, structure, and efficiency, highlighting the dynamics of high-quality development. Can factor coupling become a new driving force for high-quality economic transformation? Based on this, this paper uses Group Mean Panel FMOLS to construct a high-quality development measurement model, and uses Granger and other test methods to empirically study the internal mechanism of factor coupling and high-quality development. The results show that effective coupling provides a source of power for a stable and high-quality economic development model, and vice versa, it becomes the shackles of its development.
\end{abstract}

Keywords: Pearl River Delta, Hong Kong and Macau SAR (Special Administrative Region), Factor coupling, High-quality development, Mechanism.

\section{INTRODUCTION}

In the context of China's economy entering a new normal, economic growth is slowing, internal development momentum is insufficient, and the transformation of contradictions focuses on the quantity and quality of economic growth. How to promote and improve the high-quality development model has become the top priority. The same is true for the economy. The higher the quality of the economy, the stronger the economic stability and the more stable the cornerstone of comprehensive national strength. Without the long-term growth and development of the social economy, the economy and society cannot develop in a healthy, sustained, and comprehensive manner. The quality of economic growth is the basis for the coupling of financial and economic structural elements. Without healthy and sustained economic growth, the coupling of financial and economic structural elements lacks a strong foundation for economic support; without the effective coupling of the two, the "double wings" that drive economic development will become a "single wing", and economic quality growth will become water without a source. Therefore, the systematic study of the mechanism of coupling and high-quality development not only has important theoretical value for the construction of the region, but also has great practical significance in promoting highquality economic development.

\section{LITERATURE REVIEW}

\subsection{Foreign Research Status}

As far as the transition of economic growth is concerned, since Goldsmith put forward the financial structure theory, Levine et al. revised and supplemented when studying the internal mechanism of factor coupling and high-quality development. The non-neutral role of the financial structure on the real economy has been affirmed.

Taking structure as an element, Beck, Levine (2002), Binh et al (2006), Allen et al (2016) argue that: economic structure determines financial structure, and financial structure has an inverse effect on economic structure.

Analyzing the factors affecting the growth of economic quality, the research of King and Levine 
(1993), Aretis (1997), Rousseau and Wachtel (2000), Bech and Levine (2004) and other scholars showed that: financial market and its stability, market rate of return, financial Elements such as structure interact and influence economic quality growth. The characteristics of the economy determine the changes and optimization of the financial structure.

\subsection{Chinese Research Status}

At the beginning of the new century, many domestic scholars pay close attention to its structural relationship. For example, Yin Mengbo and He Guosheng (2001) focused on the southwestern region of my country. The results of empirical research on the interactive relationship between finance and economic structure show that with foreign scholars Consistent with the proposition. The research of $\mathrm{Li}$ Maosheng et al. (2001) shows that the financial structure is an individual, the economic structure is the whole, and the financial structure is relatively independent, which promotes the optimization of the economic structure and further drives the economic development. Fang Haowen (2013) believes that the Economic spillover effects are constrained by the financial structure.

Li Xijiang (2012) argues that the financial structure matches the economic structure, and the problem of regional financial structure development imbalance is prominent. Mao Dingxiang (2006) argued that my country's financial structure and economic structure are incompatible with each other. Sun Jingde et al. (2012) believe that financial structure and economic structure have matching symmetry. After co-integrating and testing the relationship between my country's financial structure, economic structure, and industrial structure, Dong Yingying et al. (2013) proposed that structural coupling highlights benign interactions, and economic, financial and industrial structures present a single causal relationship.

Ren Baoping (2012), Ding Renzhong (2016) took the quality of economic growth as the fulcrum, and their research results confirmed: economic efficiency, economic quality, economic structure, economic stability, and social and economic welfare (producers and Consumer surplus) and other elements restrict the transformation of kinetic energy of economic growth-the improvement from quantity to quality.
To sum up, by combing and analyzing different literatures on the coupling of economics, financial institutions, and the quality of economic growth, it can be concluded that there are more studies on the partial relationship of the three, but less on the whole, and the theoretical framework system for the study has not yet been formed. There is a lack of systematic research on the impact of the coupling of finance and economic structure on economic quality growth, and empirical research is in its infancy.

\section{RESEARCH DESIGN}

\subsection{Constructing an Econometric Model of High-quality Economic Development and Proposing Assumptions}

\subsubsection{Research Condition Assumption}

Based on $\mathrm{Y}=\mathrm{A} \boldsymbol{K}^{\alpha} \boldsymbol{L}^{1-\alpha}$ (neo-classical theory), incorporating financial and economic structural factors, the following conditional assumptions are made:

- Condition hypothesis 1: economic growth a is catalyzed by economic structure adjustment.

- Condition hypothesis 2: optimizing the financial structure is conducive to economic development and growth.

- Condition hypothesis 3: there is coupling effect between the interaction terms of economic and financial structure (positive or negative).

\subsubsection{Econometric Model Construction}

Considering the long-term nature of economic development and the influence of other factors such as income and system, the econometric model is constructed as follows:

\section{$\boldsymbol{G}_{y}=\boldsymbol{\alpha}+\boldsymbol{\beta}_{1} \mathbf{E S}+\boldsymbol{\beta}_{2} \mathbf{F S}+\boldsymbol{\beta}_{3} \mathbf{E S} * \mathbf{F S}+\mathbf{X}+\mu$}

In the models, Gy presents economic growth, ES presents economic structure, FS presents financial structure and $\mathrm{ES}^{*} \mathrm{FS}$ refers to the coupling effect between economic structure and financial structure, and $\mathrm{X}$ is other factors.

\subsection{Research Method}

By use of the method of Group Mean Panel FMOLS, through empirical research, this paper uses Granger causality to test the coordination 
mechanism of economic and financial structure as two-wing drive of economic quality growth, and finds that there may be ectopic to some extent.

\subsection{Data Sources and Description Variables}

The data are from the wind database, and the China Statistical Yearbook, and Hong Kong and Macau Statistical Yearbooks. The explained variable is expressed by the logarithm of per capita GDP, ES=TIV/GDP, Tertiary industry value is abbreviated TIV; FS=SMV/TFA, SMV stands for stock market value, and TFA is expressed as total financial assets.

\section{MODE OF ECONOMIC QUALITY GROWTH}

The test of the unit root and cointegration relationship is because whether the time series of the variable is stable, whether the random unit root exists or not, and whether there is a cointegration relationship within the variable, has an impact that cannot be ignored on the empirical analysis (for example, If the stationarity test of the time series is ignored, it will cause distortion of the estimation results, the cointegration relationship and the causality test). The condition of the cointegration test is the existence of unit roots and single integrals of the same order. Its purpose is to explore the characteristics of the data and confirm the construction model, fully affirms or denies causality.

\subsection{Unit Root Test}

Taking into account the heterogeneity of the regional panel data, a variety of methods such as ADF are used to verify the results. The results show that after the difference processing, the variables are single-integrated with the same order, and linear combinations may have a co-integration relationship. Using the Kao test as the reference standard, the Pedroni (1997) method was used to test the $\mathrm{T}$ and $\mathrm{P}$ values. The results showed that the statistical variables support the null hypothesis, and the relationship between the ADF panel and the statistics between the groups showed a significant level. Through the co-integration equation, the independent variable coefficients are analysed, and the effects of the economic and financial structure variables in different regions and the coupling of the two on the growth of economic quality are compared.

\subsection{Regression Analysis}

FMOLS method of inter-group mean panel was selected for measurement regression, and the results are shown in "Table 1".

Table 1. Regression result

\begin{tabular}{|c|c|c|c|c|}
\hline Variable & Model I & Model II & Model III & Model IV \\
\hline ES & $0.097^{* 3 *}$ & $0.158^{3.83}$ & $0.107^{3.38}$ & $0.148^{3038}$ \\
\hline FS & $0.426^{383}$ & $0.645^{* 3 *}$ & $0.643^{3 * 3}$ & $0.670^{83}$ \\
\hline $\mathrm{ES} * \mathrm{FS}$ & & $-0.005^{383}$ & $0.005^{3.38}$ & $-0.013^{*}$ \\
\hline
\end{tabular}

The results of Model 1 show that the significance of the independent variables is very prominent at the $1 \%$ level, which fully proves that economic growth comes from the transformation of economic factors, so as to verify the validity of hypotheses 1 and 2.

Model 2 shows that due to the differences in regional economic factors, considering after the negative cross-term ES*FS coefficient and very significant (i.e. $1 \%$ standard), it proves that, that is, the coupling effect is not good and high-quality economic development cannot be achieved.
Model 3 and 4 are obtained by regression of high and low income groups after considering the per capita income in 2019. Model 3 shows that the degree of mutual coupling between their structures has reached "matching", realizing high-quality economic development and growth. Model 4 shows that the cross-term coefficients of low-income groups are negative, which indicates that the negative effect of coupling between economic structure and financial structure brings about a "single-wing vibration" for economic growth, and the high-quality economic development and growth are inhibited, that is, there is a certain degree of "extra-situ". 


\subsection{Granger Causality Tests}

After differential processing, all variables become stable series, so that the three pairs of Granger causality analysis of economic quality growth, economic structure and financial structure can be carried out, and they can be tested one by one. (See the "Table 2", "Table 3", "Table 4" below).

The results of "Table 2" show that the growth of economic quality is the Grange reason for the economic structure adjustment, indicating that economic structure optimization is its Grange result.
In terms of the relationship between economic quality growth and financial structure, all regions have a one-way causal relationship, indicating that financial structure is the reason for their highquality development (see "Table 3").

The changes in the (financial) factor structure of Hong Kong and Macau are the result rather than the cause, which stems from the optimization of the economic structure, while the Granger causality mentioned above does not exist in China and the Pearl River Delta. This situation is shown in "Table $4 "$.

Table 2. Granger causality test between economic quality growth and economic structure

\begin{tabular}{|c|c|c|c|c|c|c|}
\hline \multirow[t]{2}{*}{ Area } & \multicolumn{3}{|l|}{$\mathrm{ES}{ }_{\mathrm{f} y \mathrm{y}}$} & \multicolumn{3}{|l|}{ Gy ${ }^{1} \mathrm{ES}$} \\
\hline & $\mathrm{F}$ & $P$ & $\mathrm{~K}$ & $\mathrm{~F}$ & $P$ & $\mathrm{~K}$ \\
\hline Hong Kong & $4.83142^{=1}$ & 0.0466 & 2 & $479243^{m}$ & 0.0294 & 2 \\
\hline Macau & $4.85016^{11}$ & 0.083 & 2 & $4.71055^{m}$ & 0.0298 & 2 \\
\hline pearl River Delta & 3.16817 & 0.1673 & 4 & $4.99105^{m=}$ & 0.0362 & 4 \\
\hline China & 2.66826 & 0.1408 & 4 & $4.98133^{=1}$ & 0.0334 & 4 \\
\hline
\end{tabular}

a Note: $¥$ It means "non-Granger reason", and the lag period is 4.

Table 3. Granger causality test between economic quality growth and financial structure

\begin{tabular}{|c|c|c|c|c|c|c|}
\hline \multirow[t]{2}{*}{ Area } & \multicolumn{3}{|l|}{ FS ${ }^{y y}$} & \multicolumn{3}{|l|}{$\mathrm{Gy} F \mathrm{FS}$} \\
\hline & ADF & $t$ & $\mathrm{k}$ & ADF & $\mathrm{t}$ & $\mathrm{k}$ \\
\hline Hong Kong & $14.8253^{\max }$ & 0.0007 & 2 & 1.23015 & 0.3611 & 2 \\
\hline Macau & $15.0025^{m x}$ & 0.0103 & 2 & 1.25096 & 0.3721 & 2 \\
\hline pearl River Delta & $20.6018^{\operatorname{mx}}$ & 0.0018 & 4 & 1.68926 & 0.2834 & 4 \\
\hline China & $19.7259^{\max }$ & 0.0008 & 4 & 1.66525 & 0.2607 & 4 \\
\hline
\end{tabular}

a Note: 琽 means "non-Granger reason", and the lag period is 4.

Table 4. Granger causality test of economic structure and financial structure

\begin{tabular}{|c|c|c|c|c|c|c|}
\hline \multirow[t]{2}{*}{ Area } & \multicolumn{3}{|l|}{$\mathrm{ES}+\mathrm{f} F$} & \multicolumn{3}{|c|}{$\mathrm{FS} \geq \mathrm{ES}$} \\
\hline & $\mathrm{F}$ & $p$ & $\mathrm{k}$ & $\mathrm{F}$ & $p$ & $\mathrm{k}$ \\
\hline Hong Kong & $6.26123^{m}$ & 0.0262 & 1 & 0.00079 & 0.9814 & 1 \\
\hline Macau & $6.56323^{m x}$ & 0.0323 & 1 & 0.00108 & 0.9928 & 1 \\
\hline pearl River Delta & 1.95184 & 0.3464 & 2 & 0.21349 & 0.8968 & 2 \\
\hline China & 1.49567 & 0.2647 & 2 & 0.18027 & 0.8624 & 2 \\
\hline
\end{tabular}

a Note:. $¥$ It means "non-Granger reason", and the lag period is 4

\section{THEORETICAL ANALYSIS OF THE INTERNAL MECHANISM OF ECONOMIC QUALITY GROWTH}

From a macro perspective, it is assumed that the social economy is composed of productive traditional economic (ie, real economy) sectors and non-productive emerging sectors. When the productive traditional economic sectors match the desirable capital ratios of non-productive emerging sectors, the social economic will achieve highquality development and growth. With this as a condition, a theoretical analysis of its internal mechanism will lay a rock for the empirical study on coupling of economic factors and high-quality development. 


\subsection{Mechanism of Coupling}

Based on the above assumptions, the traditional economic sector $\mathrm{M}$ is composed of sub-sector M1 and sub-sector M2. M1 is the traditional industry sector, and M2 is the traditional financial sector. Similarly, the composition of the emerging economic sector $\mathrm{N}$ corresponds to it, as shown in "Figure 1".

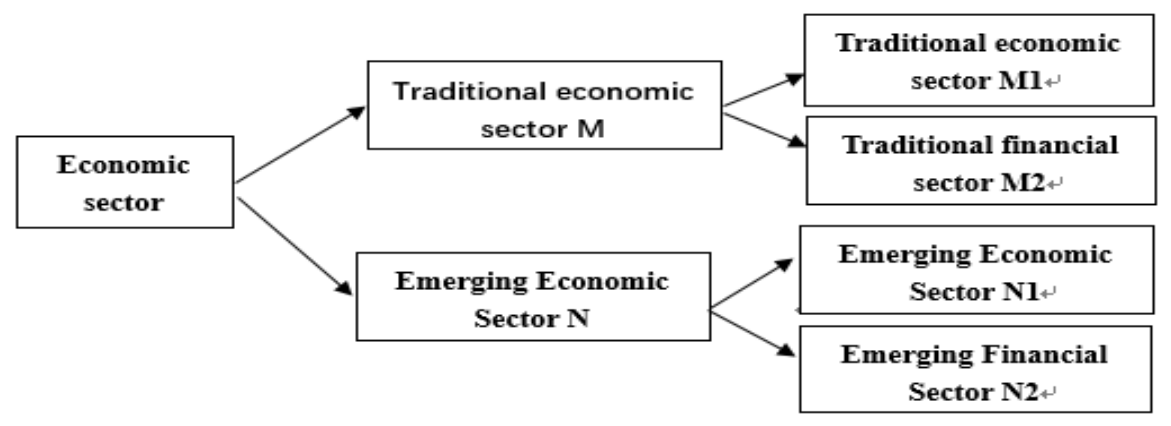

Figure 1 Different sectors of the social economy.

Drawing lessons from Yang Lin and Li Jianwei (2002) to construct a production function model, taking into account the relationship between capital stock, investment and depreciation $(\Delta \mathrm{K}=\mathrm{I}-\delta \mathrm{K})$, the specific model is as follows:

$$
\mathrm{Y}=\mathrm{F}\left(\mathrm{K}_{\mathrm{m}}, \mathrm{K}_{\mathrm{n}}\right)
$$

\section{Constraints: $\mathrm{K}_{\mathrm{m}}+\mathrm{K}_{\mathrm{n}}=\mathrm{K}, \Delta \mathrm{K}=\mathrm{I}-\mathrm{\delta K}$}

Among them, $\mathrm{K}_{\mathrm{m} 1}+\mathrm{K}_{\mathrm{m} 2}=\mathrm{K}_{\mathrm{m}}, \mathrm{K}_{\mathrm{n} 1}+\mathrm{K}_{\mathrm{n} 2}=\mathrm{K}_{\mathrm{n}}$, $\mathrm{K}_{\mathrm{m} 1}$ and $\mathrm{K}_{\mathrm{m} 2}$ are the capital stocks of traditional industries and traditional financial sectors respectively. $K_{n 1}$ and $K_{n 2}$ are the capital stocks of emerging industries and emerging financial sectors respectively.

When the economy is in a balanced development situation and the desirable capital matching ratios within the two major sectors $\left(\mathrm{K}_{\mathrm{m}}^{*}=\mathrm{K}_{\mathrm{m} 2}^{*} / \mathrm{K}_{\mathrm{m} 1}^{*}\right.$ and $\left.\mathrm{K}_{\mathrm{n}}^{*}=\mathrm{K}_{\mathrm{n} 2}^{*} / \mathrm{K}_{\mathrm{m} 1}^{*}\right)$ are reasonable, the economic and financial structure is stable, and the two major sectors are showing a steady growth trend.

With the sustained and balanced development of the economy and the growth of national income, people's demand for new products continues to increase, breaking the stability of the products and industrial structure of the original traditional economic sectors, leading to the replacement and transformation of the economic structure. At the same time, the emerging economic sector urgently requires the emerging financial sector to provide more financial product investment and large-scale continuous and effective multi-faceted financial services, while the traditional financial sector has been unable to meet the demand. In the process of upgrading and optimizing the economic structure, the capital stock of traditional economic sectors $\mathrm{K}_{\mathrm{m}}$ tends to decline, and the capital stock of emerging sectors $\mathrm{K}_{\mathrm{n}}$ tends to rise. This means that investment in emerging sectors is gradually increasing, and the opposite is true for traditional sectors.

According to the economist Hugh Patrick's "demand-following" theory, the upgrading and optimization of the economic structure has led to changes in the financial structure and the largescale economy, which will inevitably require the financial sector to provide economic entities with a variety of new financial products and services. It can be seen that, compared with the traditional economic sector $\mathrm{M}$, the emerging economic sector $\mathrm{N}$ needs more financial services, that is, the proportion of sector N's financial capital increases.

Although sector N's new investment increment or capital stock is restricted by sector budget constraints, in the process of coupling, due to the new financial service orientation and financial element benefits induced by emerging economic entities, social resources flow from traditional economic sectors into emerging economies. The economic sector, that is, the specific form of expression: $\Delta \mathrm{Kn}_{2}>\Delta \mathrm{K}_{\mathrm{m} 2} ; \Delta \mathrm{K}_{\mathrm{n} 1}<\Delta \mathrm{K}_{\mathrm{m} 1}$.

In short, with the changes in the coupling of economic factors, resources flow out of traditional economic sectors and flow into emerging economic sectors, and the internal capital stock movement trajectory is: the direction is opposite, and the amount of outflow and inflow varies. The surplus is transferred to the emerging financial sector, and the amount of capital flowing into the emerging financial sector is greater than the amount of capital flowing out of the traditional financial sector. This 
indicates that the financial services required by the emerging economic sector after the optimization of the economic structure are higher than that of the traditional economic structure.

\subsection{Research on the Motivation of High- quality Development and Coupling Mechanism}

According to the above analysis, if the economic structure is upgraded and optimized, and the emerging economic sectors that produce the same quantity of products need to increase investment, the investment in the emerging economic sectors will increase, and the investment in the traditional economic sectors will decrease. At the same time, due to the shift of capital stock flow from the traditional economic sector $M$ to the emerging sector $\mathrm{N}$, based on $\Delta \mathrm{K}=\mathrm{I}-\delta \mathrm{K}$, if depreciation is not taken into account, the investment in the traditional sector will decrease by the same amount, and the investment in the emerging economic sector will increase by the same amount. That is, $\Delta \mathrm{K}=\Delta \mathrm{I}_{\mathrm{m}}=\Delta \mathrm{I}_{\mathrm{n}}$.

According to the acceleration principle of "investment-multiplier", the emerging sector $\mathrm{N}$ can only increase the output by increasing the investment of $\mathrm{In}$, that is, $\Delta \mathrm{Yn}=\mathrm{In} /(1-\mathrm{In})$. In the same way, the output of the traditional department $M$ decreases, that is, $\Delta Y \mathrm{~m}=\mathrm{Im} /(1-\mathrm{Im})$. Because $\mathrm{In}>\mathrm{Im}, \quad$ and $\quad \Delta \mathrm{Im}=\Delta \mathrm{In}, \quad \Delta \mathrm{Yn}=\mathrm{In} / \quad(1-\mathrm{In})$ $>\Delta \mathrm{Ym}=\mathrm{Im} /(1-\mathrm{Im})$.

That is, $\Delta \mathrm{Yn}-\Delta \mathrm{Ym}>0$, indicating that the output caused by the increase in investment in the emerging economic sector $\mathrm{N}$ is greater than the output reduced by the traditional economic sector $\mathrm{M}$, then the entire social economic output increases during the coupling process of the economic and financial structure, and the economic development is in a steady growth Situation.

\section{CONCLUSION}

In conclusion, this article analyzes the linkage mechanism between economic factor coupling and high-quality development and the above empirical results, and draws the following conclusions: economic structure and financial structure are linear with economic quality growth, and the coupling of economic and financial structures presents a positive or negative effect on the growth of economic quality.
Through the analysis of different regional economic entities, taking Hong Kong and Macao SAR as reference, it provides beneficial practical experience and enlightenment for the sustainable, stable and high-quality economic development in the new era. First of all, from the perspective of economic structure transformation and financial structure optimization, it is the primary factor for the regional economic growth to build an effective mechanism of complementary advantages and synergetically coupled development, and improve the coupling density of economic factors. Secondly, it is to clarify the focus of the economic development of the three places, determine the different desirable capital ratios within the economic and financial structure, accurately implement dynamic monitoring and control of the desirable capital ratio, and return to a reasonable match and balance between the two.

\section{AUTHORS' CONTRIBUTIONS}

Shizhong Xiong contributed to the design and revision of the paper, and Xiaofang Xiong carried out the data analysis.

\section{REFERENCES}

[1] Yin Mengbo, He Guosheng. The relationship between financial structure and economic structure in Southwest China [J]. Economist, 2001, (6): 17-24. (in Chinese)

[2] Li Maosheng, Li Guangrong. Research on the optimization of economic structure and financial structure at the beginning of the new century $[\mathrm{J}]$. Economic Research in Theory and Practice of Finance and Economics, 2001, (6) 17-24. (in Chinese)

[3] Li Xijiang. Economic structure adjustment and financial tool selection: from regional differences [J]. Reform, 2012, (8): 25-30. (in Chinese)

[4] Sun Jingde, Yu Xiamin. The Ningbo case of the relationship between financial structure and macroeconomic structure $[\mathrm{J}]$. Shanghai Finance, 2012, (8): 21-25. (in Chinese)

[5] Dong Yingying, Liao Kegui. An Empirical Study on the Relationship between China's Financial Structure and Macroeconomic Structure [J]. Statistics and Decision, 2013, (6): 159-161.(in Chinese) 
[6] Fang Haowen. Research on the Relationship between Financial Structure, Economic Structure and Total Consumption Volatility Based on the View of Financial Constraint $[\mathrm{J}]$. Journal of Tianjin University: Social Science Edition, 2013, (3): 204-209.(in Chinese)

[7] Yang Lin, Li Jianwei. Financial structure transformation and real economic structure upgrade (Part 1) [J]. Finance and Trade Economics, 2002, (2): 9-11. (in Chinese)

[8] Ren Baoping. The quality of economic growth: theoretical interpretation, basic propositions and ethical principles $[\mathrm{J}]$. Academic Monthly, 2012, 44(02): 63-70. (in Chinese)

[9] Ding Renzhong. Political economic analysis on supply-side structural reforms [J]. Economist, 2016, (3): 13-15. (in Chinese)

[10] Xiong Shizhong. Research on the Mechanism of the Optimization of Financial and Economic Structure on the Economic Growth of Guangdong, Hong Kong and Macao [J]. Contemporary Economy, 2020, (8): 36-40. (in Chinese)

[11] Arestis, P., P. Demetriades. Financial Development and Economic Growth: Assessing the Evidence [J]. Economic Journal, 1997, 107:783-799.

[12] Allen, Bartiloro, Kowalewski. Does Economic Structure Determine Financial Structure? [D]. Ieseg Working paper Series, 2016.

[13] Binh, Park, Shin. Financial structure Does Matter for Industrial Growth: Direct Evidence from OECD Countries [D].Working paper, 2006.

[14] Beck, Levine. Industry growth and capital allocation: Does having a market - or bankbased system matter [J]. Journal of Financial Economics, 2002, 64(2):147-180.

[15] King, R. G. R. Levine. Finance, Entrepreneuship, and Growth: Theory and Evidence $[\mathrm{J}]$. Journal of Monetary Economics, 1993,32:513-542.

[16] Rousseau, P. L., P. Wachtel. Equity Markets and Growth: Cross-Country Evidence on Timing and Outcomes, 1980-1995 [J]. Journal of Business and Finance, 2000, 24:1933-1957.
[17] Beck, T. and R. Levine. Stock Markets, Banks and Growth: Panel Evidence [J]. Journal of Banking and Finance, 2004: 423-442.

[18] Goldsmith R W. Financial Structure and Development [M]. New Haven, CT: Yale University Press, 1969.21-35. 